Pendrin abundance was observed in aldosteroneinfused animals. Additionally, chloride's role was highlighted during an oral kidney session at the conference. Dr. Puyol (Buenos Aires, Argentina) presented the effect of the anion chloride on the induction of oxidative stress on a high-salt diet. This revealed the chloride anion was associated with more glutathione peroxidase activity than the sodium cation in the kidney cortex, favoring a prooxidative state.

Outside of the kidney, Dr. Constantino ladecola (NY, USA) revealed the mechanisms associated with high salt intake and cognitive impairment. In animal studies, high salt, independently of blood pressure levels, induces endothelial dysfunction in the brain. This process is mediated by II-17 generated in $\mathrm{TH} 17$ lymphocytes at the intestine, highlighting the role of the gut-brain axis. Thus, II-17 in cerebral arteries decreases endothelial nitric oxide synthase (eNOS), decreasing cerebral blood flow but also increasing accumulation of the phosphorylated Tau protein. These elegant studies showed that the salt-induced Tau protein, induced by high salt, and not decreased blood flow, induced the cognitive impartment. Thus, future clinical trials should translate these findings to prevent cognitive impairment in patients.

Overall, the ESH-ISH Meeting has contributed new concepts and translational evidence on the role of a high-salt diet in hypertension and hypertensionmediated organ damage.

\section{References:}

1.Rakova N, Kitada K, Lerchl K, Dahlmann A, Birukov A, Daub S, et al. Increased salt consumption induces body water conservation and decreases fluid intake. J Clin Invest. 2017;127(5):1932-43. DOl: 10.1172/ $\mathrm{JCl} 88530$

2.Romero CA, Carretero OA. A Novel Mechanism of Renal Microcirculation Regulation: Connecting Tubule-Glomerular Feedback. Curr Hypertens Rep. 2019;21(1):8. DOI: 10.1007/s11906-019-0911-5

\title{
Salt and Hypertension - Clinical Aspects
}

\section{NEUSA JESSEN \\ Unidade de Investigação, Departamento de Medicina do Hospital Central de Maputo, Maputo, Moçambique.}

DOI:10.30824/2106-8

The clinical importance of high blood pressure has been recognized for almost two centuries now ${ }^{1}$ but its etiopathogenesis is still a matter of continuing intense research. Although effective treatment is available, control of blood pressure (BP) remains a global challenge and hypertension continues to be the main risk factor for morbidity and mortality around the world ${ }^{2}$. The simplified and concise 2020 International Society of Hypertension Global Hypertension Practice Guidelines will harmonize the management for worldwide healthcare providers ${ }^{3}$ while the search for more effective ways of preventing and controlling hypertension continues. It is well stablished that the onset of hypertension may be prevented, or at least delayed, by healthy lifestyle choices ${ }^{4}$, which is also the first line of antihypertensive treatment.

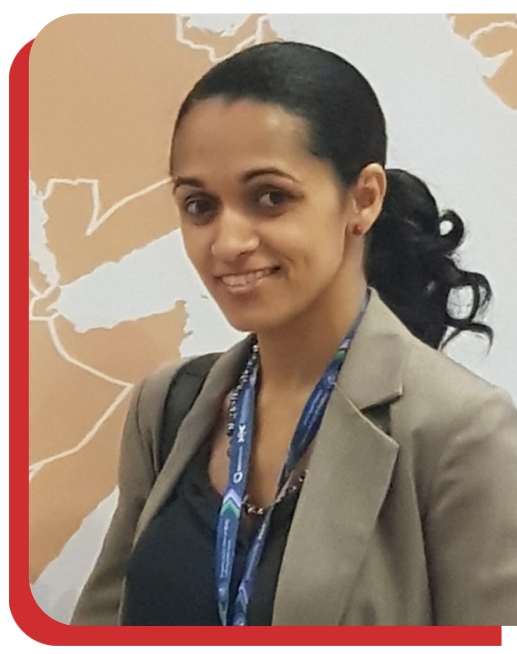

Salt intake is considered the most important dietary risk factor for hypertension, and, in fact, a large body of evidence supports the strong association between high $\mathrm{Na}$ intake and raised $\mathrm{BP}^{5}$. Nevertheless, the susceptibility to the BP-raising effects of salt, called salt sensitivity of BP (SSBP), is a physiological quantitative trait that varies between individuals and the mechanisms that mediate the pressor effects of salt are not fully explained ${ }^{6}$. Furthermore, although the associations between high sodium intake and increased BP as well as between hypertension and cardiovascular (CV) morbidity and mortality are well stablished and undisputed, the question of impact of dietary salt reduction in hard CV outcomes (stroke, myocardial infarction or death) remains unanswered, with several studies presenting opposed results ${ }^{5}$. As 
such, it remains a matter of continued attention and discussion. Recently, Professor Franz Messerli and colleagues analysed the relationship between sodium intake and life expectancy and survival?. Global health estimates of 181 countries were used to analyse the relationship between countryspecific average sodium consumption with healthy life expectancy (at birth and at 60 years), death due to non-communicable diseases and allcause mortality for the year of 2010. The authors found a positive correlation between sodium intake and healthy life expectancy (including when the analysis was restricted to 46 high income countries) but not for death due to noncommunicable diseases. An inverse correlation with all-cause mortality was also observed. Though such findings suggest that high sodium intake does not shorten life span or increase premature death, a large number of potential confounders and several other limitations of the study, as well acknowledged by the authors, preclude its use as a guide for nutritional interventions. Unfortunately, conducting an adequate trial to evaluate the lifespan effect of high dietary salt in humans, which could raise definitive evidence on hard CV outcomes and mortality, is very difficult, requiring a large sample of the population, followed for a long time, with strict control of several variables. Based in current evidence, the World Health Organization recommends a daily salt intake $<5$ $\mathrm{g}^{8}$. In fact, SSBP is considered an important public health problem, independently of $\mathrm{BP}^{6,9}$ but the lack of clear mechanisms and biomarkers for this trait prevents the identification of individuals at higher risk, who could benefit from early intervention.

Promising results were presented at the joint meeting ESH-ISH 2021. Chen C. and colleagues, based on bioinformatics approaches, identified several potential biomarkers of SSBP, though pending confirmation in humans ${ }^{10}$. On the other hand, an emerging new scientific view states that the problem in SSBP is not the level of salt in the diet but an abnormal BP response to salt. Opposing to previous knowledge that there is an impairment in renal function, recent studies have shown that the changes in sodium balance and cardiac output in salt-sensitive (SS) individuals are no different from those in salt-resistant normotensives. Instead, there is an abnormal vascular resistance response to high salt intake ("vasodysfunction theory"). In effect, Professor Kurtz and colleagues argued that instead of reducing salt in food, what should be corrected is the mechanism causing such abnormal response. Taking into account previous evidence showing that in SS individuals there is an abnormal reduction of nitric oxide activity that impairs vascular relaxation leading to hypertension, their studies showed that the administration of small amounts of nitrates (in the form of sodium nitrate or beetroot juice) and nitrite (in the form of sodium nitrite) protects against salt induced increases of BP, in Dalh salt sensitive rats and Spontaneously Hypertensive Stroke Prone (SHRSP) rats, respectively ${ }^{11}$. Tiny amounts of nitrate protected against large amounts of salt, with nitrates appearing to be 100 times more potent than potassium for protecting against salt-induced hypertension. Accordingly, salty food fortification with small amounts of nitrate-rich vegetable extracts was proposed as a strategy to prevent salt-induced hypertension without changing the diet.

Though this may be a way forward to protect against the effects of high salt intake in BP, what was not evaluated in these studies and should be considered when designing public health interventions and in future research, is that increasing BP is not the only deleterious health effect of high salt intake. It has been shown that salt can damage target organs by several other pathways, being independently associated to the risk of numerous other important public health problems $^{12}$. In practice, the ideal strategy would require the identification of the SS individuals and the main mechanisms of salt-induced hypertension in their specific settings (accounting for the influence of ethnicity and culture in the BP response to salt), to inform tailored interventions. Presently, no simple, accurate and widely accepted method of estimating dietary sodium intake and no clear guidance as to how to manage the patient are available. Pending further evidence, for the health professional in front of the patient, the use of questionnaires to assess individual salt intake, such as the one presented by Bortolotto L. et al (sodium consumption questionnaire with photographic manual), is an accessible alternative to the 24-hour urinary collection and can guide individualized dietary advice. It could be adapted and validated for specific contexts.

\section{References:}

1.Kotchen TA. Historical trends and milestones in hypertension research: a model of the process of translational research. Hypertension. 2011;58(4):52238. DOI: 10.1161/HYPERTENSIONAHA.111.177766 
2.Murray CJL, Aravkin AY, Zheng P, Abbafati C, Abbas KM, Abbasi-Kangevari M, et al. Global burden of 87 risk factors in 204 countries and territories, 1990-2013;2019: a systematic analysis for the Global Burden of Disease Study 2019. The Lancet. 2020;396(10258):1223-49. DOI: 10.1016/ S0140-6736(20)30752-2

3.Unger T, Borghi C, Charchar F, Khan NA, Poulter NR, Prabhakaran D, et al. 2020 International Society of Hypertension Global Hypertension Practice Guidelines. Hypertension. 2020;75(6):1334-57. DOI: 10.1161/HYPERTENSIONAHA.120.15026

4.Appel LJ, Brands MW, Daniels SR, Karanja N, Elmer PJ, Sacks FM. Dietary approaches to prevent and treat hypertension: a scientific statement from the American Heart Association. Hypertension. 2006;47(2):296-308. DOI: 10.1161/01. HYP.0000202568.01167.B6

5. He FJ, Tan M, Ma Y, MacGregor GA. Salt Reduction to Prevent Hypertension and Cardiovascular Disease: JACC State-of-the-Art Review. Journal of the American College of Cardiology. 2020;75(6):632-47. DOl: 10.1016/j.jacc.2019.11.055

6.Elijovich F, Weinberger MH, Anderson CA, Appel LJ, Bursztyn M, Cook NR, et al. Salt Sensitivity of Blood Pressure: A Scientific Statement From the American Heart Association. Hypertension. 2016;68(3):e7-e46. DOI: 10.1161/HYP.0000000000000047
7.Messerli FH, Hofstetter L, Syrogiannouli L, Rexhaj E, Siontis GCM, Seiler C, et al. Sodium intake, life expectancy, and all-cause mortality. European Heart Journal. 2020. DOI: 10.1093/eurheartj/ehaa947

8.World Health Organization (WHO). Guideline: sodium intake for adults and children. https://www. who.int/publications/i/item/9789241504836; 2012.

9.Mishra S, Ingole S, Jain R. Salt sensitivity and its implication in clinical practice. Indian heart journal. 2018;70(4):556-64. DOI: 10.1016/j.ihj.2017.10.006

10.Chen C, Liu G-Z, Liao Y-Y, Chu C, Zheng W-L, Wang $Y$, et al. Identification of Candidate Biomarkers for Salt Sensitivity of Blood Pressure by Integrated Bioinformatics Analysis. Frontiers in Genetics. 2020;11(988). DOI: 10.3389/fgene.2020.00988

11. Morris RC, Pravenec M, Šilhavý J, DiCarlo SE, Kurtz TW. Small Amounts of Inorganic Nitrate or Beetroot Provide Substantial Protection From Salt-Induced Increases in Blood Pressure. Hypertension. 2019;73(5):1042-8. DOI: 10.1161/ HYPERTENSIONAHA.118.12234

12. Farquhar WB, Edwards DG, Jurkovitz CT, Weintraub WS. Dietary sodium and health: more than just blood pressure. Journal of the American College of Cardiology. 2015;65(10):1042-50. DOI: 10.1016/j.jacc.2014.12.039

\section{Join ISH now}

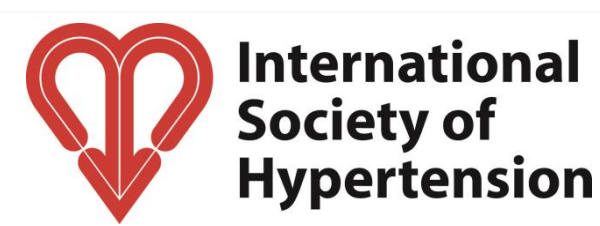

Members from HINARI countries are eligible to pay reduced membership fees.

\section{ISH RESEARCH FELLOW FREE}

An opportunity for young researchers/clinical scientists undertaking a higher degree or a postdoctoral fellowship, to enhance their CV. 3 year term limit.

\section{ISH EMERGING LEADER \$140 annually}

A special opportunity for mid-career research and clinical scientists.

\section{ISH PROFESSIONAL MEMBERSHIP \$185 annually}

For investigators who have accomplished meritorious original investigation in the field of hypertension or are heavily involved with clinical or educational activities.

\section{ISH HEALTH PROFESSIONAL AFFILIATES \$40}

For healthcare delivery and Allied Health Professionals such as nurses, pharmacists, dietitians, or healthcare workers.

\section{FELLOW OF THE ISH $\$ 250$}

The election as a Fellow honors members of the Society who have distinguished themselves through excellence in clinical practice or research in the field of Hypertension. https://ish-world.com/membership/join.htm 